\title{
Rosuvastatin and vascular dysfunction markers in pulmonary arterial hypertension: a placebo-controlled study
}

\author{
A.C. Barreto ${ }^{1}$, N.Y. Maeda², R.P.S. Soares ${ }^{2}$, C. Cícero ${ }^{1}$ and A.A. Lopes ${ }^{1}$ \\ ${ }^{1}$ Departamento de Cardiologia Pediátrica e Cardiopatias Congênitas do Adulto, Instituto do Coração, \\ 2LIM-31, Faculdade de Medicina, Universidade de São Paulo, São Paulo, SP, Brasil \\ Correspondence to: A.A. Lopes, Departamento de Cardiologia Pediátrica e Cardiopatias Congênitas do \\ Adulto, InCor, HC, FMUSP, Av. Dr. Eneas de Carvalho Aguiar, 44, 05403-000 São Paulo, SP, Brasil \\ Fax: +55-11-3069-5409. E-mail: aablopes@usp.br
}

\begin{abstract}
We investigated whether chronic rosuvastatin administration could improve the abnormalities of the circulating levels of vascular dysfunction markers in pulmonary arterial hypertension $(\mathrm{PAH})$. Sixty patients, aged 13 to 60 years, with idiopathic ( $\mathrm{N}=14$ ) or congenital heart disease-associated $\mathrm{PAH}(\mathrm{N}=46)$ were equally but randomly assigned to rosuvastatin treatment (10 mg a day, orally) or placebo for 6 months in a blind fashion. Plasma levels of P-selectin, tissue-plasminogen activator and its inhibitor as well as von Willebrand factor antigen were measured by enzyme-linked immunoassay before and after 1,3 , and 6 months of treatment. Baseline levels of biomarkers were elevated $(68,16,45$ and $46 \%$ increase relative to controls, for P-selectin, von Willebrand factor antigen, tissue-plasminogen activator and its inhibitor, respectively; $P<0.001)$. P-selectin values at baseline, 1,3 , and 6 months were $39.9 \pm 18.5,37.6 \pm 14.6,34.8 \pm 14.6$, and $35.4 \pm 13.9 \mathrm{ng} / \mathrm{mL}$, respectively, for the rosuvastatin group and $45.7 \pm 26.8,48.0 \pm 26.9,48.1 \pm 25.7$, and $45.7 \pm 25.6 \mathrm{ng} / \mathrm{mL}$ for the placebo group. The P-selectin level was lower in the rosuvastatin group compared with placebo throughout treatment $(P=0.037$, general linear model). $A$ trend was observed towards a decrease in tissue-plasminogen activator in the statin group ( $16 \%$ reduction, $P=0.094)$, with no significant changes in the other markers. Since P-selectin is crucial in inflammation and thrombosis, its reduction by rosuvastatin is potentially relevant in the pathophysiological scenario of $\mathrm{PAH}$.
\end{abstract}

Key words: Pulmonary hypertension; Statins; Endothelial dysfunction; P-selectin; Tissue-plasminogen activator and inhibitor; von Willebrand factor

Research supported by FAPESP (\#05/50320-5).

Received January 22, 2008. Accepted August 14, 2008

\section{Introduction}

The treatment of pulmonary arterial hypertension (PAH) has changed in the last decades with the development of new drugs, including prostanoids, endothelin antagonists and phosphodiesterase inhibitors (1-7). Most clinical studies have demonstrated beneficial effects of these drugs on physical capacity, quality of life, hemodynamics, and survival. In the clinical setting, these agents were initially proposed as vasodilators, but experimental data suggest that they may also act on vessel walls. However, the effects of drugs on circulating levels of vascular dysfunc- tion markers and other biomarkers have been explored to a lesser extent, mostly for prostacyclin administration (811).

Vascular dysfunction (involving endothelial cells, platelets and leukocytes) is an important event in PAH (12). Altered circulating levels of endothelial markers have been observed in association with increased risk of thrombosis and decreased survival (13-15). Therefore, the improvement of vascular dysfunction with drug therapy might have an impact on the risk of thrombotic complications and mortality in these patients. Statins are among the drugs that have been proposed in this context. They are capable 
of reversing experimental pulmonary hypertension, an effect that may be related to over-expression or protection of endothelial nitric oxide synthase $(16,17)$ and/or changes in the expression of several other genes associated with inflammatory, proliferative and apoptotic mechanisms (18), including the bone morphogenetic protein type II receptor gene in human lung microvascular endothelial cells (19).

The present study was planned to investigate the effects of chronic statin administration versus placebo on the circulating levels of vascular dysfunction markers in patients with either idiopathic $\mathrm{PAH}$ or that associated with congenital heart disease. We also measured the 6-min walked distance and resting as well as postexercise peripheral oxygen saturation as exploratory clinical variables. Since a direct vasodilator effect of the drug was not expected, all patients with class III symptoms were assigned to vasodilator therapy before they entered the study.

\section{Material and Methods}

\section{Study population}

Adolescents and adults with $\mathrm{PAH}$, either idiopathic or associated with congenital heart disease, in the absence or presence of hypoxemia (resting $\mathrm{SpO}_{2}$ of $\geq 90$ or $<90 \%$, respectively) were enrolled. They were receiving medical care at the Heart Institute, São Paulo, Brazil, as outpatients with stable clinical conditions (functional class II or III, New York Heart Association). A mean pulmonary arterial pressure of $>30 \mathrm{mmHg}$ at rest was necessary for inclusion. Patients with an angio CT showing extensive thrombotic lesions in the pulmonary arteries were excluded. All patients with class III symptoms were started on vasodilator therapy (oral sildenafil, $20-40 \mathrm{mg}$, three times a day) 1-2 months before entering the study. For patients with stable class II symptoms, vasodilator therapy was considered after completion of the present study. The majority of patients were on chronic anticoagulant therapy with warfarin, and some were using diuretics and/or digoxin. We planned not to change baseline treatment during the study period, unless clearly necessary in case of clinical deterioration. All subjects with congenital heart disease had increased pulmonary vascular resistance and were considered to be unsuitable for surgical correction. Those with abnormal peripheral oxygen saturation were continuously monitored in terms of hydration, hematocrit level, iron stores, hyperviscosity symptoms, thrombotic or bleeding episodes and need for hemodilution. The study protocol was approved by the Scientific Committee of the Heart Institute, and the Ethics Committee of the Hospital of Clinics, School of Medicine, University of São Paulo. Written informed consent was obtained from all patients (or their parents in case of adolescents) before inclusion in the study.

\section{Randomization and study design}

Despite the controversy about having variables under control prior to randomization, for this specific study we opted to ensure absolute group homogeneity regarding four clinical variables. Thus, having met the inclusion criteria, patients were consecutively organized into pairs according to age (difference $<10$ years), diagnosis (idiopathic or congenital heart disease-associated $\mathrm{PAH}$ ), resting peripheral oxygen saturation $(<80,80-89, \geq 90 \%)$ and use of vasodilator drugs. In each pair, 1 patient was randomly assigned to placebo and the other to rosuvastatin treatment, $10 \mathrm{mg} / \mathrm{day}$, single oral dose (nested case-control randomized study). Randomization was carried out using a pre-established computer-based sequence. The operator was completely separated from patient care. $\mathrm{Pa}-$ tients were maintained on treatment in a double-blind fashion for 6 months, and the treatment code was opened when the last patient completed the follow-up period.

\section{Clinical and laboratory measurements}

Demographic data were collected before treatment was begun. The functional class, 6-min walked distance and resting as well as postexercise (6-min walk) peripheral oxygen saturation were recorded before and during treatment (1, 3, and 6 months). For safety purposes, the circulating levels of creatinine phosphokinase and hepatic enzymes (alanine, aspartate aminotransferases and $\gamma$-glutamyltranspeptidase) were determined at the same times.

Plasma levels of vascular dysfunction markers were measured before treatment and 1, 3, and 6 months after treatment using commercially available high-sensitivity enzyme-linked immunosorbent assay kits purchased from Diagnostica Stago, France, for tissue-plasminogen activator (t-PA), plasminogen activator inhibitor-1 (PAI-1), and von Willebrand factor antigen (vWF:Ag) or from R\&D Systems Inc., USA, for P-selectin. Determinations were carried out in duplicate. Intra-assay variation and differences between duplicates were always less than $5 \%$. A control plasma from our laboratory was run in parallel in all assays. Corrections between assays (between kits) were never necessary. Final results were obtained after normalization for the hematocrit level.

A control group was selected, with the same age range as the patients. The group consisted of 30 healthy volunteers, mostly blood donors. For inclusion, a brief questionnaire was applied in order to exclude acute or chronic illness, in particular diabetes, hypertension and other cardiovascular disorders. Only non-smokers were enrolled. A 
negative history for thrombophilia and/or deep vein thrombosis was an inclusion requirement.

\section{Statistical analysis}

Variables were tested for closeness to the normal distribution, and results are reported as means and standard deviation (or standard error of the mean if specifically indicated) or if not a normal distribution as median and range. Baseline data were analyzed using the Student $t-$ test. The overall treatment effects on the biomarkers were analyzed using a general linear model with two factors (type of treatment and time), and repeated measures for one of them (time). Thus, the study was primarily designed to analyze the effect of the drug compared with placebo during the entire 6-month period, not just at 6 months. PAI1 values were analyzed after logarithmic transformation. In all tests, 0.05 was considered to be the level of significance. Statistical analysis was carried out using the SPSS statistical software, version 14.0 (SPSS Inc., USA).

\section{Results}

Sixty patients (36 females) were enrolled $(\mathrm{N}=30$ each for placebo and statin groups), with age ranging from 13 to 60 years (median 33 years) and mean pulmonary arterial pressure of $53 \pm 16 \mathrm{mmHg}$. These patients were in functional class II $(\mathrm{N}=50)$ or III $(\mathrm{N}=10)$, and the disease was either idiopathic $(\mathrm{N}=14)$ or associated with congenital heart defects in the absence $(\mathrm{N}=18)$ or presence $(\mathrm{N}=28)$ of hypoxemia. All subjects in functional class III had idiopathic pulmonary arterial hypertension and were on vasodilator therapy.

When all of the 60 class II or III patients on placebo or drug were analyzed before treatment, the circulating levels of the four biomarkers were higher $(P<0.001)$ when compared with healthy controls (Table 1). Before treatment, placebo and statin groups were similar in terms of age, 6-min walked distance, peripheral oxygen saturation, and plasma levels of all four biomarkers (Table 2).

The effects of rosuvastatin treatment on the biomarkers are shown in Figures 1 and 2. The P-selectin level was significantly lower in the statin (filled circles) compared with placebo (open circles) at all times during treatment $(P$ $=0.037$ ). The placebo group P-selectin levels at 1,3 , and 6 months were $48.0 \pm 26.9,48.1 \pm 25.7$, and $45.7 \pm 25.6 \mathrm{ng} /$ $\mathrm{mL}$, respectively, and for the statin group, they were $37.6 \pm$ 14.6, $34.8 \pm 14.6$, and $35.4 \pm 13.9 \mathrm{ng} / \mathrm{mL}$ compared to healthy controls, $25.5 \pm 10.3 \mathrm{ng} / \mathrm{mL}$ and normal value reported by the kit manufacturer, $29.0 \pm 11.0 \mathrm{ng} / \mathrm{mL}$. No significant effects of rosuvastatin were observed for PAI-1 or von Willebrand factor, except for a trend towards a decrease in t-PA levels $(P=0.094$; Figure 1$)$. There were no statistical differences between patient subgroups (idiopathic versus congenital heart disease-associated $\mathrm{PAH}$ and hypoxemic versus non-hypoxemic subjects).

In both placebo and rosuvastatin groups, no increase in the 6-min walked distance was observed from baseline to 6 months. In the specific diagnostic subgroup of hypoxemic patients with congenital heart disease $(N=28), 8$ of 14 patients on placebo, but only 1 of 14 patients on rosuvastatin had a decrease in postexertional peripheral oxygen saturation at 6 months compared with pretreatment data $(P=0.013$, Fisher exact test; Figure 3).

All patients completed the study, and the following events were observed: clinical deterioration requiring combined vasodilator therapy (1 patient, placebo group); he-

Table 1. Plasma levels of biomarkers in patients $(N=60)$ and controls $(N=30)$ before treatment.

\begin{tabular}{lcc}
\hline & Controls & Patients \\
\hline P-selectin $(\mathrm{ng} / \mathrm{mL})$ & $25.5 \pm 10.3$ & $42.8 \pm 23.0^{*}$ \\
t-PA $(\mathrm{ng} / \mathrm{mL})$ & $5.91 \pm 1.71$ & $8.57 \pm 3.95^{*}$ \\
vWF:Ag $(\mathrm{U} / \mathrm{dL})$ & $105 \pm 25$ & $122 \pm 23^{*}$ \\
PAl-1 $(\mathrm{ng} / \mathrm{mL})$ & $16.5(5.2-42.9)$ & $24.1(9.7-134.7)^{*}$ \\
\hline
\end{tabular}

Data are reported as mean $\pm \mathrm{SD}$, except for PAl-1 (median and range). t-PA = tissue-type plasminogen activator; vWF:Ag = von Willebrand factor antigen; $\mathrm{PAl}-1$ = plasminogen activator inhibitor-1.

${ }^{*} \mathrm{P}<0.001$ (Student $t$-test).

Table 2. Placebo and rosuvastatin groups ( $N=30$ each) before treatment.

\begin{tabular}{lcc}
\hline & Placebo & Rosuvastatin \\
\hline Age (years) & $33.7 \pm 11.1$ & $34.6 \pm 12.3$ \\
6MWD $(\mathrm{m})$ & $415 \pm 110$ & $416 \pm 103$ \\
Rest SpO $(\%)$ & $91 \pm 4 \%$ & $90 \pm 6 \%$ \\
$6 \mathrm{MW} \mathrm{SpO} 2(\%)$ & $78 \pm 12 \%$ & $74 \pm 17 \%$ \\
P-selectin (ng/mL) & $45.7 \pm 26.8$ & $39.9 \pm 18.5$ \\
t-PA (ng/mL) & $9.00 \pm 4.04$ & $8.14 \pm 3.38$ \\
vWF:Ag (U/dL) & $122 \pm 24$ & $122 \pm 22$ \\
PAl-1 (ng/mL) & $23.9(9.7-134.7)$ & $24.5(9.8-103.3)$ \\
\hline
\end{tabular}

Data are reported as mean $\pm \mathrm{SD}$, except for PAI-1 (median and range). $6 \mathrm{MWD}=6$-min walked distance; $\mathrm{SpO}_{2}=$ peripheral oxygen saturation; $6 \mathrm{MW} \mathrm{SpO}_{2}=$ postexertional (6-min walk) peripheral oxygen saturation; $\mathrm{t}-\mathrm{PA}=$ tissue-type plasminogen activator; vWF:Ag = von Willebrand factor antigen; PAI-1 = plasminogen activator inhibitor- 1 . There were no statistically significant differences between groups for any of the parameters (Student $t$-test). 
moptysis (1 patient, statin group); syncope at 6 months during the walk test (1 patient, placebo group); insomnia ( 3 patients, statin group); skeletal muscle pain (2 patients, 1 from statin group, with transient creatinine phosphokinase elevation above three times normal level); $\gamma$-glutamyltranspeptidase elevation above three times normal (1 patient, placebo group).

\section{Discussion}

In this placebo-controlled study, chronic oral administration of rosuvastatin to $\mathrm{PAH}$ patients resulted in a statistically significant decrease in the circulating level of $\mathrm{P}$ selectin for an average of $10 \%$ and a trend towards a decrease in t-PA level in patients with $\mathrm{PAH}(\mathrm{P}=0.094$, general linear model). The plasma levels of the other markers of vascular dysfunction, vWF:Ag, tissue-plasminogen activator, and its inhibitor did not change with statin treatment but were significantly higher than in healthy subjects.

Only 1 patient presented transient elevation of plasma creatinine phosphokinase level associated with skeletal muscle pain attributable to rosuvastatin treatment. While analyzing the options in terms of selecting the statin that could be used in the present study, rosuvastatin was chosen because it is a third-generation hydrophilic statin, relatively well tolerated at daily doses of 10 to $40 \mathrm{mg}$, and metabolized via cytochrome p450 (CYP) 2C9 and does not
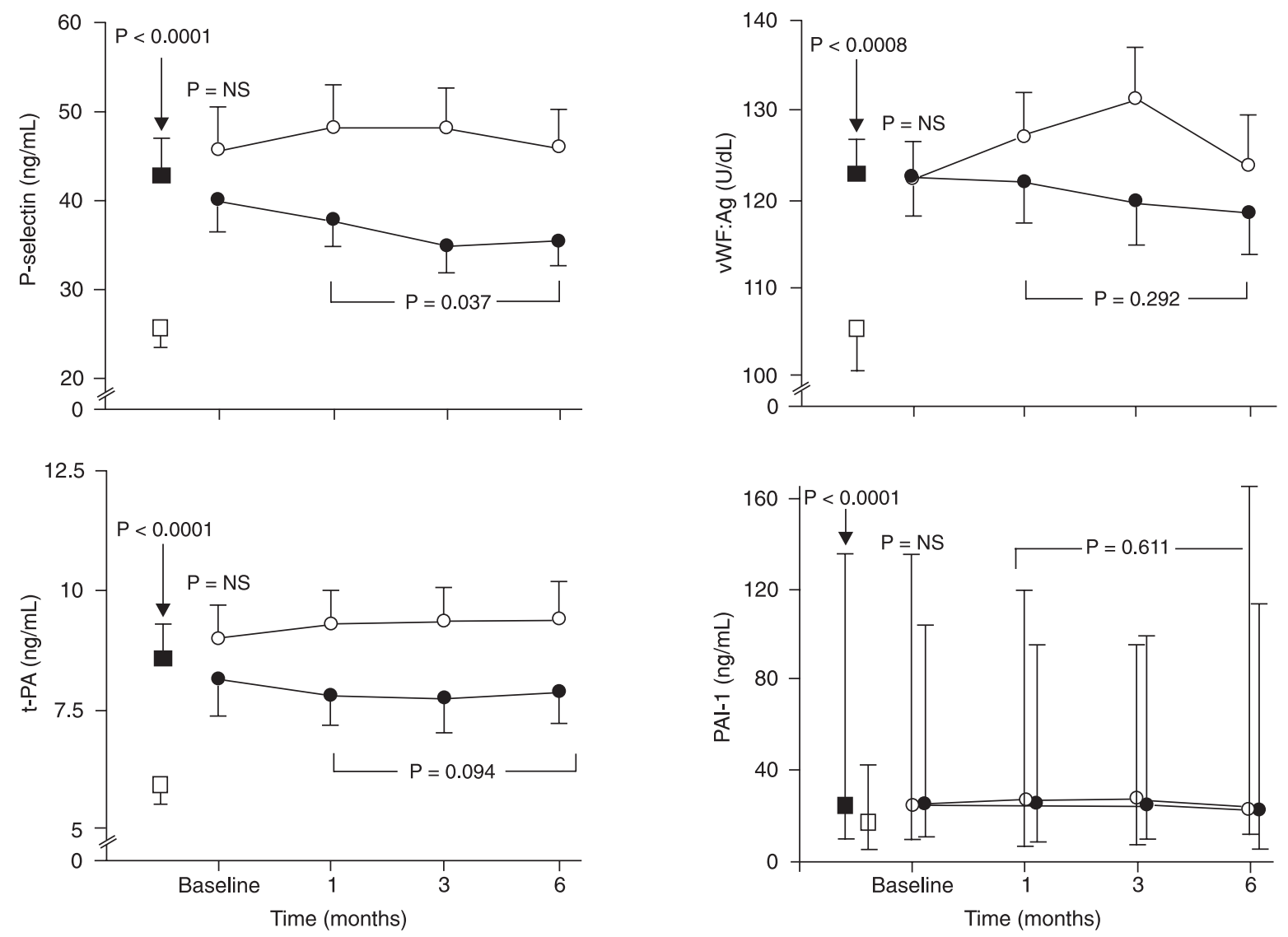

Figure 1. Treatment-related behavior of endothelial markers in patients with pulmonary arterial hypertension. Before treatment with rosuvastatin (10 mg/day), plasma levels of all four biomarkers were significantly higher ( $P$ values in the upper left side of the panels, Student $t$-test) in patients (closed square) compared with controls (open square). Rosuvastatin $(\mathrm{N}=30$, closed circles) induced a significant decrease in the circulating level of P-selectin compared with placebo $(N=30$, open circles), with no significant effect on the other markers. $P$ values in the right side of the panels correspond to the analysis of the entire period of treatment (general linear model for two factors). Results are reported as mean \pm SEM for P-selectin, tissue-plasminogen activator (t-PA), and von Willebrand factor antigen (vWF:Ag), and as median value and range for plasminogen activator inhibitor-1 (PAl-1). 

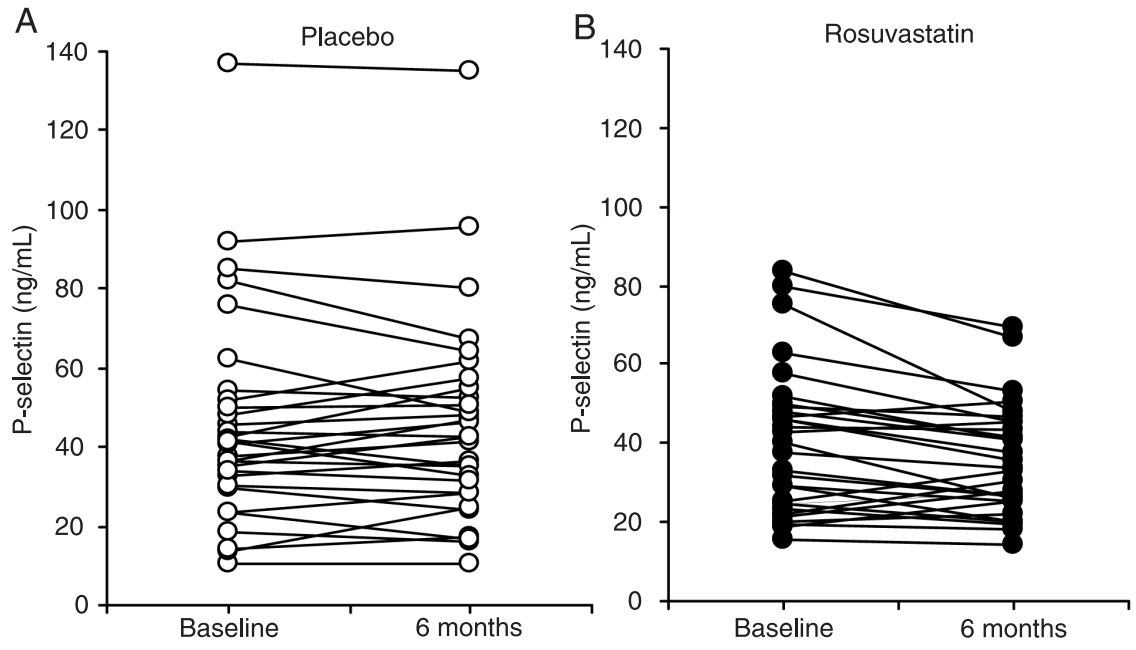

A

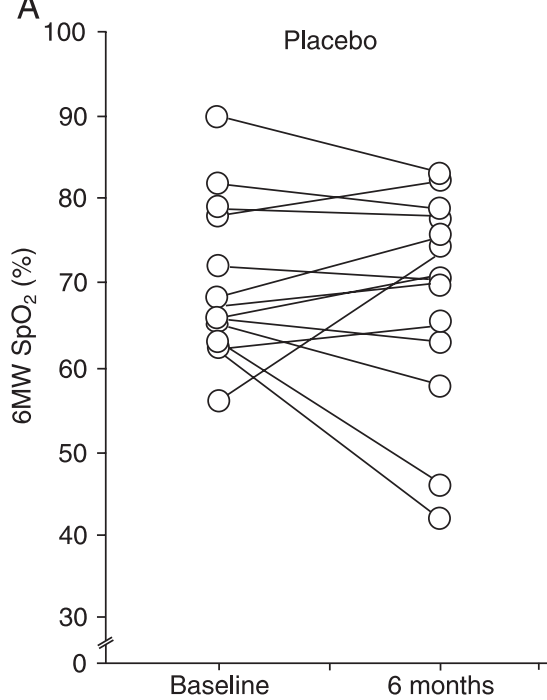

B

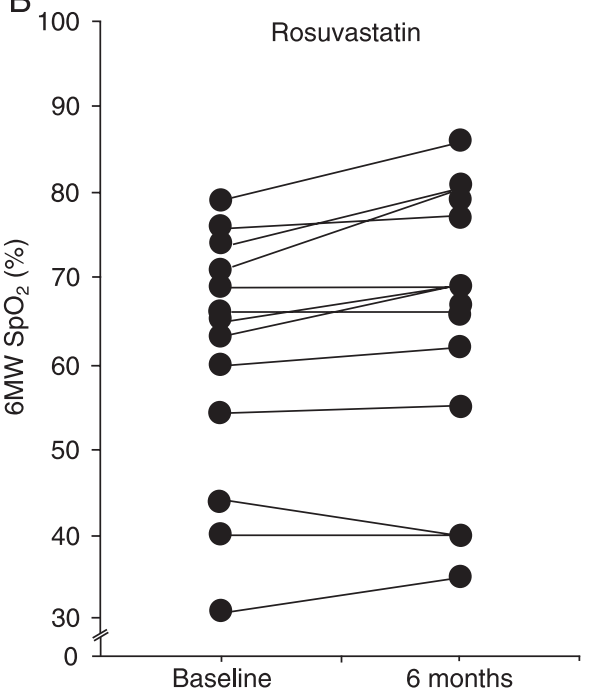

Figure 2. Plasma P-selectin levels in patients with pulmonary arterial hypertension. The results observed at baseline and 6 months of treatment with placebo $(A, N=30$, open circles) or rosuvastatin $(B, N=30$, closed circles) are shown $(P=0.0041$ and $P$ $=0.9744$ for rosuvastatin and placebo groups, respectively, Student $t$-test).
Figure 3. Postexertional (6-min walk) peripheral oxygen saturation $6 \mathrm{MW}$ $\mathrm{SpO}_{2}$ ) in individual patients with pulmonary hypertension associated with congenital heart disease and hypoxemia at rest. The results obtained at baseline and 6 months of treatment with placebo $(A, N=14$, open circles) or rosuvastatin $(B, N=14$, closed circles) are shown. Deterioration occurred to a lesser extent in the rosuvastatin group compared with patients on placebo. The mean \pm SD values of $6 \mathrm{MW} \mathrm{SpO}$ at baseline and 6 months, respectively, were $70 \pm 9$ and $68 \pm 13 \%$ for the placebo group $(\mathrm{P}=0.6106$, Student $t$-test), and $61 \pm$ 14 and $64 \pm 16 \%$ for the statin group ( $\mathrm{P}=0.0129$, Student $t$-test). interact with many drugs that use the CYP $3 \mathrm{~A} 4$ pathway (20-22)

Beneficial effects of statins have been reported in experimental pulmonary hypertension, particularly in hypoxic conditions (23-25). These effects may be related, in part, to protection of endothelial cell nitric oxide synthase (26), but changes in the expression of several genes associated with inflammation, cell proliferation and apoptosis have been reported $(18,19)$.

Two of the four biomarkers investigated in this study are adhesion molecules (P-selectin and von Willebrand factor), while the others (t-PA and PAl-1) are a serine- protease and its inhibitor primarily involved in the fibrinolytic process. Although plasma levels of all four markers were elevated at baseline, only P-selectin was significantly reduced by rosuvastatin treatment compared with placebo. The graphs shown in Figure 1 demonstrate differences in the distributions of the plasma markers, with a great variability of PAI-1 values, followed by vWF:Ag, and less variable values of $\mathrm{P}$-selectin and $\mathrm{t}-\mathrm{PA}$.

$\mathrm{P}$-selectin and von Willebrand factor originate from both platelets and endothelial cells. Endothelial P-selectin and von Willebrand factor are stored within the WeibelPalade bodies and released by a number of stimuli includ- 
ing hypoxia (27). Released molecules may circulate or become attached to the plasma membrane. While von Willebrand factor is involved in platelet adhesion and aggregation, $\mathrm{P}$-selectin plays a pivotal role in leukocyte movement slowing down (particularly polymorphonuclear cell rolling) at the endothelial surface. Indeed, exocytosis of endothelial cell Weibel-Palade bodies has been shown to cause rapid neutrophil recruitment, an event that is inhibited in the presence of a blocking antibody to P-selectin (28). Also, interactions between these adhesion molecules are expected to occur in vivo, as P-selectin appears to anchor von Willebrand factor multimers to the endothelial cell membrane (29). Thus, if we assume that circulating (soluble) P-selectin reflects the amount of membranebound molecules attributable to endothelial dysfunction and/or platelet activation $(10,30)$, lowered plasma level as a result of rosuvastatin treatment might be associated with diminished interactions of leukocytes and platelets with the endothelium, an important therapeutic goal to be achieved in this disease.

\section{References}

1. Barst RJ, Rubin LJ, Long WA, McGoon MD, Rich S, Badesch $\mathrm{DB}$, et al. A comparison of continuous intravenous epoprostenol (prostacyclin) with conventional therapy for primary pulmonary hypertension. The Primary Pulmonary Hypertension Study Group. N Engl J Med 1996; 334: 296-302.

2. Galie N, Humbert M, Vachiery JL, Vizza CD, KneussI M, Manes A, et al. Effects of beraprost sodium, an oral prostacyclin analogue, in patients with pulmonary arterial hypertension: a randomized, double-blind, placebo-controlled trial. J Am Coll Cardiol 2002; 39: 1496-1502.

3. Olschewski H, Simonneau G, Galie N, Higenbottam T, Naeije R, Rubin LJ, et al. Inhaled iloprost for severe pulmonary hypertension. N Engl J Med 2002; 347: 322-329.

4. Rubin LJ, Badesch DB, Barst RJ, Galie N, Black CM, Keogh A, et al. Bosentan therapy for pulmonary arterial hypertension. N Engl J Med 2002; 346: 896-903.

5. Simonneau G, Barst RJ, Galie N, Naeije R, Rich S, Bourge $R C$, et al. Continuous subcutaneous infusion of treprostinil, a prostacyclin analogue, in patients with pulmonary arterial hypertension: a double-blind, randomized, placebo-controlled trial. Am J Respir Crit Care Med 2002; 165: 800-804.

6. Barst RJ, Langleben D, Frost A, Horn EM, Oudiz R, Shapiro $\mathrm{S}$, et al. Sitaxsentan therapy for pulmonary arterial hypertension. Am J Respir Crit Care Med 2004; 169: 441-447.

7. Galie N, Ghofrani HA, Torbicki A, Barst RJ, Rubin LJ, Badesch D, et al. Sildenafil citrate therapy for pulmonary arterial hypertension. N Engl J Med 2005; 353: 2148-2157.

8. Boyer-Neumann C, Brenot F, Wolf M, Peynaud-Debayle E, Duroux $P$, Meyer $D$, et al. Continuous infusion of prostacyclin decreases plasma levels of t-PA and PAI-1 in primary pulmo-
In view of the lipid lowering action of rosuvastatin and the known proinflammatory properties of LDL cholesterol, one could argue that the observed statin effect on $\mathrm{P}$ selectin could be indirect, via LDL cholesterol reduction. This is an obvious limitation of the study, since we did not address this point specifically. However, lipid lowering, if this was the case, would not be a definite proof in favor of an indirect effect of rosuvastatin.

In this study, rosuvastatin treatment appeared to be associated with some protection against deterioration in postexertional peripheral oxygen saturation in hypoxemic patients. Also, when all patients were analyzed as a whole, there was a mild improvement of $15 \mathrm{~m}$ over placebo in terms of the 6-min walked distance. However, since the study was not designed and not powered to examine these effects, we decided to report them just as exploratory clinical findings that could stimulate future investigation. Statins are unlikely to substitute for any of the currently used drugs for $\mathrm{PAH}$, but may have a place as adjunct therapy if further observations support their recommendation. nary hypertension. Thromb Haemost 1995; 73: 735-736.

9. Friedman R, Mears JG, Barst RJ. Continuous infusion of prostacyclin normalizes plasma markers of endothelial cell injury and platelet aggregation in primary pulmonary hypertension. Circulation 1997; 96: 2782-2784.

10. Sakamaki F, Kyotani S, Nagaya N, Sato N, Oya H, Satoh T, et al. Increased plasma P-selectin and decreased thrombomodulin in pulmonary arterial hypertension were improved by continuous prostacyclin therapy. Circulation 2000; 102 : 2720-2725.

11. Veyradier A, Nishikubo $T$, Humbert $M$, Wolf $M$, Sitbon $O$, Simonneau G, et al. Improvement of von Willebrand factor proteolysis after prostacyclin infusion in severe pulmonary arterial hypertension. Circulation 2000; 102: 2460-2462.

12. Budhiraja R, Tuder RM, Hassoun PM. Endothelial dysfunction in pulmonary hypertension. Circulation 2004; 109: 159165.

13. Galiè N, Grigioni F, Bacchi-Reggiani L, Ussia GP, Parlangeli $R$, Catanzariti $P$, et al. Relationship of endothelin-1 to survival in patients with primary pulmonary hypertension. Eur $\mathrm{J}$ Clin Invest 1996; 26 (Suppl 1): A48 (Abstract).

14. Lopes AA, Maeda NY, Goncalves RC, Bydlowski SP. Endothelial cell dysfunction correlates differentially with survival in primary and secondary pulmonary hypertension. $\mathrm{Am}$ Heart J 2000; 139: 618-623.

15. Kawut SM, Horn EM, Berekashvili KK, Widlitz AC, Rosenzweig EB, Barst RJ. von Willebrand factor independently predicts long-term survival in patients with pulmonary arterial hypertension. Chest 2005; 128: 2355-2362.

16. Murata T, Kinoshita K, Hori M, Kuwahara M, Tsubone H, 
Karaki $\mathrm{H}$, et al. Statin protects endothelial nitric oxide synthase activity in hypoxia-induced pulmonary hypertension. Arterioscler Thromb Vasc Biol 2005; 25: 2335-2342.

17. Guerard $P$, Rakotoniaina Z, Goirand F, Rochette L, Dumas $M$, Lirussi $F$, et al. The HMG-CoA reductase inhibitor, pravastatin, prevents the development of monocrotaline-induced pulmonary hypertension in the rat through reduction of endothelial cell apoptosis and overexpression of eNOS. Naunyn Schmiedebergs Arch Pharmacol 2006; 373: 401. 414.

18. Nishimura T, Vaszar LT, Faul JL, Zhao G, Berry GJ, Shi L, et al. Simvastatin rescues rats from fatal pulmonary hypertension by inducing apoptosis of neointimal smooth muscle cells. Circulation 2003; 108: 1640-1645.

19. Hu H, Sung A, Zhao G, Shi L, Qiu D, Nishimura T, et al. Simvastatin enhances bone morphogenetic protein receptor type II expression. Biochem Biophys Res Commun 2006; 339: 59-64.

20. Olsson AG, McTaggart F, Raza A. Rosuvastatin: a highly effective new HMG-CoA reductase inhibitor. Cardiovasc Drug Rev 2002; 20: 303-328.

21. Rosenson RS. Rosuvastatin: a new inhibitor of HMG-coA reductase for the treatment of dyslipidemia. Expert Rev Cardiovasc Ther 2003; 1: 495-505.

22. Cheng JW. Rosuvastatin in the management of hyperlipidemia. Clin Ther 2004; 26: 1368-1387.

23. Girgis RE, Li D, Zhan X, Garcia JG, Tuder RM, Hassoun $\mathrm{PM}$, et al. Attenuation of chronic hypoxic pulmonary hypertension by simvastatin. Am J Physiol Heart Circ Physiol
2003; 285: H938-H945.

24. Girgis RE, Mozammel S, Champion HC, Li D, Peng X, Shimoda $L$, et al. Regression of chronic hypoxic pulmonary hypertension by simvastatin. Am J Physiol Lung Cell Mol Physiol 2007; 292: L1105-L1110.

25. Souza-Costa DC, Figueiredo-Lopes L, Alves-Filho JC, Semprini MC, Gerlach RF, Cunha FQ, et al. Protective effects of atorvastatin in rat models of acute pulmonary embolism: involvement of matrix metalloproteinase-9. Crit Care Med 2007; 35: 239-245.

26. Laufs U, Fata VL, Liao JK. Inhibition of 3-hydroxy-3-methylglutaryl (HMG)-CoA reductase blocks hypoxia-mediated down-regulation of endothelial nitric oxide synthase. J Biol Chem 1997; 272: 31725-31729.

27. Michiels C, Arnould T, Remacle J. Endothelial cell responses to hypoxia: initiation of a cascade of cellular interactions. Biochim Biophys Acta 2000; 1497: 1-10.

28. Pinsky DJ, Naka Y, Liao H, Oz MC, Wagner DD, Mayadas TN, et al. Hypoxia-induced exocytosis of endothelial cell Weibel-Palade bodies. A mechanism for rapid neutrophil recruitment after cardiac preservation. J Clin Invest 1996; 97: 493-500

29. Padilla A, Moake JL, Bernardo A, Ball C, Wang Y, Arya M, et al. P-selectin anchors newly released ultralarge von Willebrand factor multimers to the endothelial cell surface. Blood 2004; 103: 2150-2156.

30. Davi G, Romano M, Mezzetti A, Procopio A, lacobelli S, Antidormi $\mathrm{T}$, et al. Increased levels of soluble P-selectin in hypercholesterolemic patients. Circulation 1998; 97: 953-957. 